Research Article

\title{
Factors Influencing the Information Service Quality of the Online Website of Hospitals in China
}

\author{
Lei Jiao $\mathbb{D}$ and Yiping Wang \\ Business College, Taizhou University, Taizhou, Zhejiang 318000, China \\ Correspondence should be addressed to Lei Jiao; leijiao@tzc.edu.cn
}

Received 7 August 2021; Revised 7 September 2021; Accepted 15 September 2021; Published 25 September 2021

Academic Editor: Muhammad Usman

Copyright (c) 2021 Lei Jiao and Yiping Wang. This is an open access article distributed under the Creative Commons Attribution License, which permits unrestricted use, distribution, and reproduction in any medium, provided the original work is properly cited.

\begin{abstract}
Internet's online information services can deliver high-quality services to the public while eliminating social alienation and virus transmission. From 2013 until the fourth quarter of 2020, China has had the highest number of Internet users in the world. Public access to information in the health care business in China is mostly through the Internet. In the healthcare business, high-quality information services are the fundamental obstacle because of their importance and effect on human lives. This article uses Chinese hospitals as a case study, covering assessment system development and empirical research. A total of 217 questionnaires were issued, 212 of which were valid, and the effective rate was 97.6 percent. The outcomes of the research show that the extensive epidemiological information services of the hospital website during an epidemic outbreak have a significant influence on the public's use of the hospital website. Secondly, high-quality epidemic-related information services are critical to enhancing website information services during outbreaks. Finally, in the epidemic, the high-quality service of the hospital's website has a greater impact on the worth of information in comparison to the content of information service.
\end{abstract}

\section{Introduction}

As per the China Internet Network Information Center (CNNIC 2019), there were 1.701 billion Chinese Internet users as of June 2019. In China, it has become the major source of news for the population [1]. Coronavirus disease (COVID-19) is a global public health emergency, as of January 30, 2020, according to the World Health Organization [2]. According to the World Health Organization, as of April 18, 2020, the virus had infected 2,310,572 individuals, killed 158,691 people, and is currently spreading. A worldwide pandemic has been triggered by the coronavirus (COVID-19), which has spread to other nations, including mainland China [3]. This virus can be prevented by avoiding contact with the virus. It may be prevented most effectively by avoiding active or passive exposure to the viral environment, according to China, the US Centers for Disease Control and Prevention, and the World Health Organization [4]. All of these methods have had a positive impact on preventing epidemics. The Chinese hospital's Internet website was used by many locals during the outbreak of the coronavirus (COVID-19) to get health and information services. Aside from the lack of study, it is unclear which elements would impact the quality of public information services on hospital websites during the pandemic.

The theoretical research platform of this study is constructed based on the initial detailed indicators of the evaluation system set mentioned previously after reviewing related theories such as the two-dimensional model of perceived quality, the model of customers' perceived service quality, SERVOUAL model, E-SQ, and OSQ. The medical information service quality of the hospital online website is jointly determined by perceived service quality and the evaluated quality of platform information. Interaction, online medical service, platform information construction, and platform information quality are four dimensions used for evaluating the perceived quality of medical information service of the hospital's online website.

In this study, the full score represents the customer's expected service quality, while the perceived service quality score is the difference between the expected and actual 
service quality. The major contribution of the paper is to provide advanced comprehensive epidemiological information services of the hospital website during a pandemic outbreak and, secondly, what affects the service quality of the hospital's online website during the COVID-19 epidemic. Thirdly, we quantitatively evaluate the service quality of the hospital's online website. Lastly, a strategy for improving the quality of hospital information services during an epidemic outbreak has been proposed utilizing network data from the hospital's online domain.

The rest of the paper is organized as follows. In Section 2, the research methodology is proposed. The performance evaluation system analysis is conducted in Section 3. The experimental results and discussion are further summarized in Section 4. Finally, Section 5 concludes the paper with a summary and future research directions.

\section{Research Methodology}

In recent years, there are many studies on the website information service. Most of them have a very direct relationship with the dimensions and attributes of the information service quality of online websites. These studies present the medical information service quality indicators of hospital online websites. These studies not only make contributions to the information service quality attributes and dimensions but also provide further studies with theoretical basis and cases. For instance, some scholars can discuss website online websites in hospitals that render both information resource service and general online service. We uncover the medical information service quality indicators of hospital online websites from the following studies.

A number of authors have proposed stage models; for example, electronic service quality (E-SQ) was defined by Parasuraman et al. [5] as the degree to which consumers can acquire and provide items or services via the Internet efficiently and effectively. Cai and Jun [6] define online service quality (OSQ) as the gap between customers' perceived and anticipated service. Webqual (Web Quality) is described by Jeon [7] as the quality of Internet technology activities. Xie et al. [8] provide an online information service. Reliability, convenience, communication efficacy, tangibles, dependability, prompt responsiveness, and consistency are all important considerations. Kolesar and Glbraith [9] described the service for online purchasing using tangibles, dependability, reactivity, and ease of use. Zeithaml et al. [10] described the service provided electronically with efficiency, dependability, and secrecy are all important considerations. Wolfinbarger and Gilly [11] described the service for electronic retail. Website design, dependability, and service security are all important considerations. Hung [12] defined website quality as "the overall quality of the website, the quality of the information, and the quality of the service." Harold and Linda [13] evaluated the quality of website services. Many more researches [14-25] focused on online marketing, credibility, service dependability, and communication, as well as user satisfaction, availability, characterization, information quantifying, and privacy, quantifying the quality of hospital online service providers.
2.1. Website Service Quality. The total information service quality of the hospital on the website is derived from the patient's perception of service quality on the hospital website and the information quality measured by the information service quality assessment system. According to the theoretical model in Figure 1, this research acquired the dimensional structure of the Chinese hospital information service quality evaluation system during the (COVID-19) pandemic after two rounds of an expert consultation. Figure 1 depicts the eight parameters for evaluating the information quality of an online website.

$$
\mathrm{FR}=\sum_{\mathrm{i}=1}^{W} \sum_{\mathrm{j}=1}^{S_{\mathrm{i}}} \mathrm{W} I_{\mathrm{ij}} S D_{\mathrm{ij}} \times 100 .
$$

2.2. Measuring Web-Based Service Quality. The information service weights and quantitative values of the online website during the COVID-19 pandemic were developed by weighing the quantitative numerical weights of the information service system assessment and talking with experts via surveys. Based on the aforesaid model, standards for Chinese hospitals and the COVID-19 pandemic Chinese hospital Internet website Information service complete assessment model and the calculation formula for the weighted total score were created. Equation (1) depicts the calculating formula.

The FR in the formula represents the final quantitative score, and the value of FR ranges from 0 to 100 . The score of FRij is the score obtained by the $j^{\text {th }}$ index in the $i^{\text {th }}$ dimension. $W I_{\mathrm{ij}}$ represents the weight of the $j^{\text {th }}$ index in the $i^{\text {th }}$ dimension. The value range of $i$ is the maximum value of $m$ and the minimum value is 1 , and the value range of $j$ is the maximum value of $n_{i}$ and the minimum value is 1 . Si represents the number of indicators in the $i^{\text {th }}$ dimension, and $W$ represents the number of dimensions. $W$ is equal to $8 . S$ is the total number of three-level indicators in the evaluation system, equal to 55 .

\section{Performance Evaluation System}

In this section, we create a quality assessment framework for web-based service quality by learning from the previous design and taking into account the distinctions between web-based services and conventional services. The comprehensive weight and calculation method of indicators of the China online hospital information service evaluation system are shown in Figure 2.

\section{Result and Discussion}

4.1. Data Collection Procedure. This empirical study will explore and assess the hospital's website. During the outbreak of coronavirus (COVID-19), on March 1, 2020, the hospital's website began reporting and providing services for coronavirus (COVID-19) information. This article covers the time node for reporting and servicing on the hospital website in this empirical investigation. Against the backdrop of the epidemic, nine empirical research surveys and data 


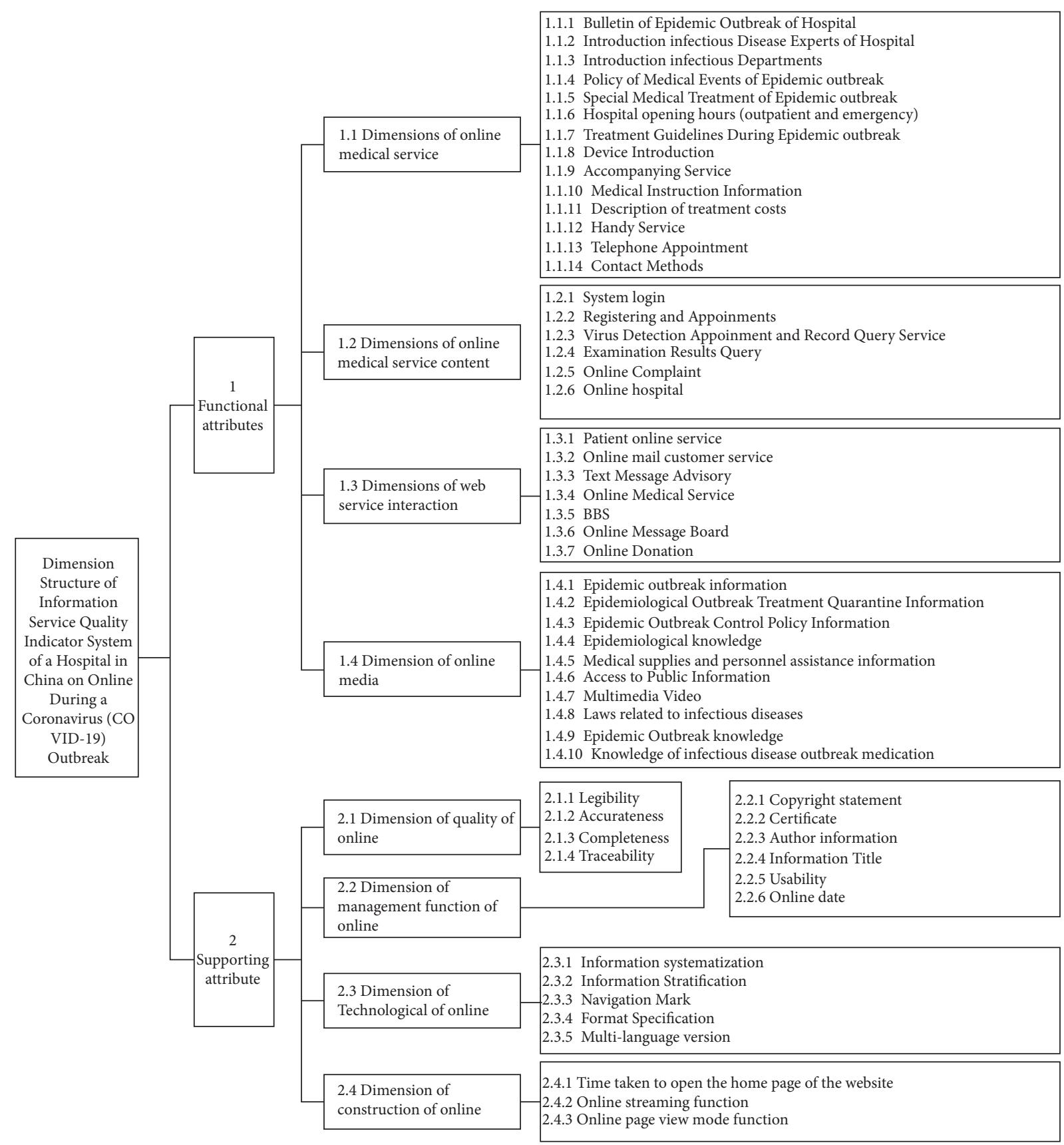

Figure 1: Dimension of a Chinese hospital on online service during the outbreak of coronavirus (COVID-19).
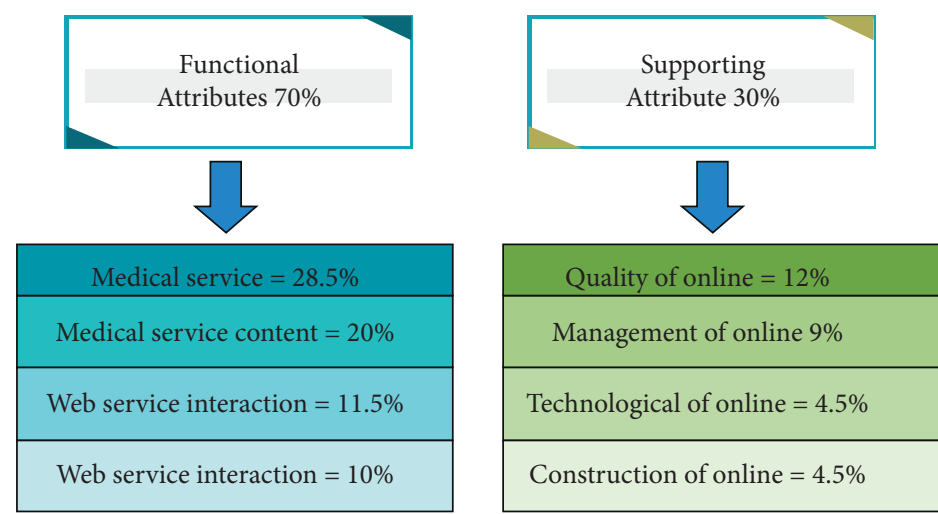

FIGURE 2: Comprehensive weights of indicators of China's online hospital information service evaluation system during the coronavirus (COVID-19) outbreak. 
TABLE 1: The composition of participants in the empirical research on the comprehensive evaluation system.

\begin{tabular}{lccc}
\hline Dimension & Item & Number & Percentage (\%) \\
\hline \multirow{4}{*}{ Users } & Outpatient & 18 & 25 \\
& Inpatient & 18 & 25 \\
& Hospital employee & 18 & 25 \\
Gender & The public and professionals & 18 & 25 \\
& Male & 42 & 58 \\
Age & Female & 30 & 42 \\
& $16-21$ & 2 & 3 \\
& $22-27$ & 20 & 28 \\
Education & $28-33$ & 30 & 41 \\
& Over 34 & 20 & 28 \\
\hline
\end{tabular}

TABLE 2: Evaluations of a hospital in China online during the coronavirus (COVID-19) outbreak.

\begin{tabular}{lcccccccccc}
\hline No. & Date & 1.1 & 1.2 & 1.3 & 1.4 & 2.1 & 2.2 & 2.3 & 2.4 & Total score \\
\hline 1 & $2020 / 2 / 3$ & 10.952 & 11.800 & 0.540 & 0.000 & 1.683 & 1.731 & 1.575 & 2.934 & 31.215 \\
2 & $2020 / 2 / 10$ & 13.607 & 11.800 & 1.860 & 0.000 & 1.785 & 1.731 & 1.575 & 2.934 & 35.292 \\
3 & $2020 / 2 / 24$ & 16.938 & 12.994 & 5.560 & 2.536 & 1.785 & 1.731 & 1.575 & 2.934 & 46.053 \\
4 & $2020 / 3 / 2$ & 18.488 & 12.994 & 5.560 & 2.536 & 1.938 & 1.731 & 1.575 & 2.934 & 47.756 \\
5 & $2020 / 3 / 16$ & 18.850 & 12.994 & 5.920 & 3.935 & 1.785 & 1.731 & 1.575 & 2.934 & 49.724 \\
6 & $2020 / 3 / 30$ & 18.850 & 12.994 & 5.920 & 3.935 & 4.418 & 4.881 & 1.527 & 2.934 & 55.459 \\
7 & $2020 / 4 / 6$ & 18.850 & 12.994 & 5.920 & 4.526 & 6.821 & 4.881 & 1.575 & 2.934 & 58.500 \\
8 & $2020 / 4 / 13$ & 18.850 & 12.994 & 6.800 & 4.526 & 7.541 & 5.637 & 1.728 & 3.380 & 61.455 \\
9 & $2020 / 4 / 27$ & 18.850 & 12.994 & 6.800 & 5.561 & 10.169 & 5.934 & 1.728 & 3.380 & 65.415 \\
\hline
\end{tabular}

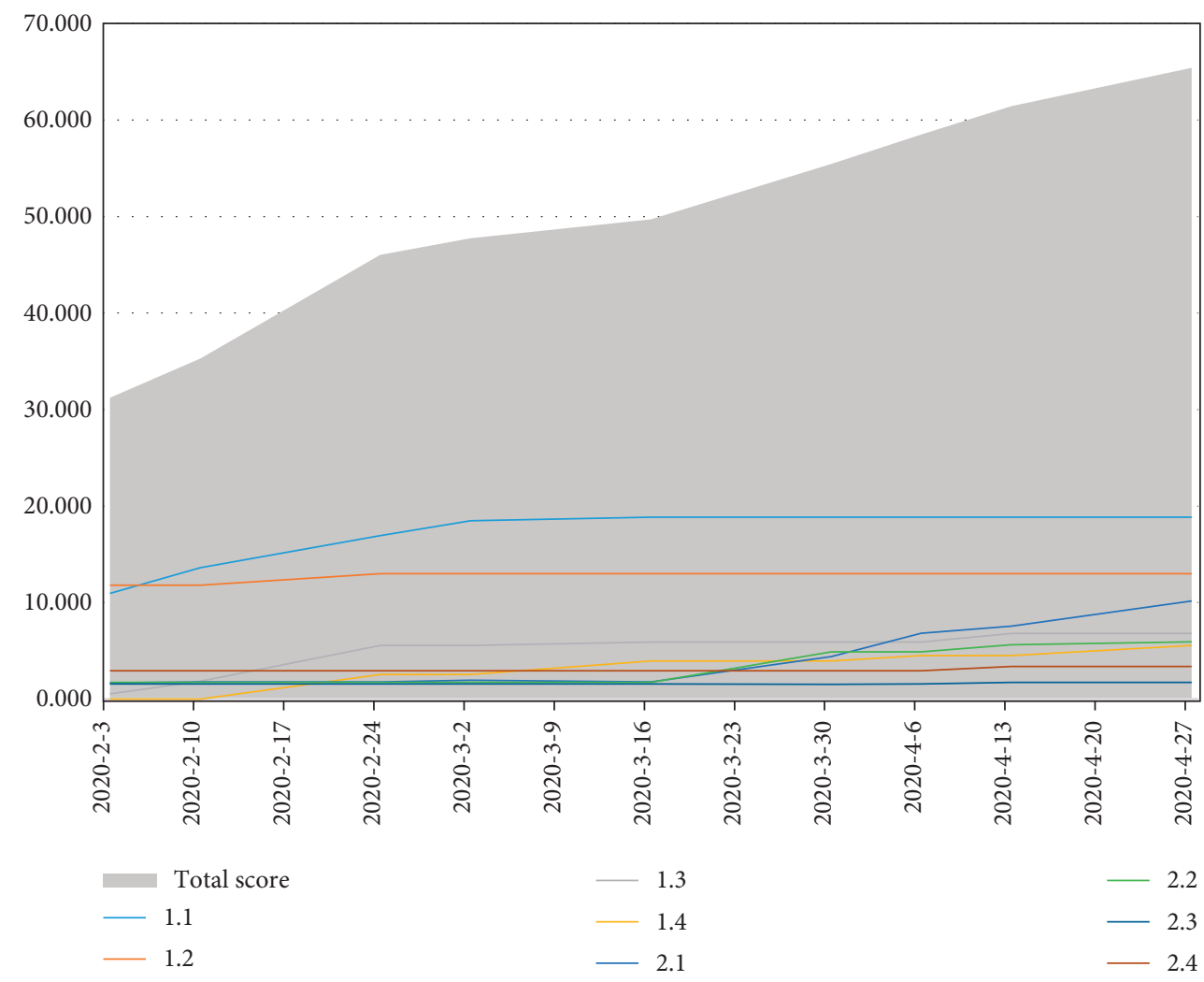

FIGURE 3: Correlation analysis of evaluations of a hospital in China online during the coronavirus (COVID-19) outbreak. 
TABLE 3: Correlation analysis of information service and the traffic of a hospital in China online during the coronavirus (COVID-19) outbreak.

\begin{tabular}{lcccc}
\hline Correlation analysis object & Pearson correlation & Sig (2-tailed) & Correlation \\
\hline Research findings and total traffic & 1.000 & 0 & Correlation is significant at the 0.01 level & 18 \\
Research findings and PV & 1.000 & 0 & Correlation is significant at the 0.01 level & 18 \\
Research findings and UV & 1.000 & 0 & Correlation is significant at the 0.01 level & 18 \\
\hline
\end{tabular}

TABLE 4: Score of a hospital online website in China of growth of rate during the coronavirus (COVID-19) outbreak.

\begin{tabular}{lccccccccccc}
\hline Date & 1 & 2 & 1.1 & 1.2 & 1.3 & 1.4 & 2.1 & 2.2 & 2.3 & 2.4 & Total score \\
\hline $2020 / 2 / 3$ & 0 & 0 & 0 & 0 & 0 & 0 & 0 & 0 & 0 & 0 & 0 \\
$2020 / 2 / 10$ & 1.17 & 1.01 & 1.24 & 1.00 & 3.44 & 0 & 1.06 & 1.00 & 1.00 & 1.00 & 1.13 \\
$2020 / 2 / 24$ & 1.39 & 1.00 & 1.24 & 1.10 & 2.99 & 0 & 1.00 & 1.00 & 1.00 & 1.00 & 1.30 \\
$2020 / 3 / 2$ & 1.04 & 1.02 & 1.09 & 1.00 & 1.00 & 1.00 & 1.09 & 1.00 & 1.00 & 1.00 & 1.04 \\
$2020 / 3 / 16$ & 1.05 & 0.98 & 1.02 & 1.00 & 1.06 & 1.55 & 0.92 & 1.00 & 1.00 & 1.00 & 1.04 \\
$2020 / 3 / 30$ & 1.00 & 1.71 & 1.00 & 1.00 & 1.00 & 1.00 & 2.47 & 2.82 & 0.97 & 1.00 & 1.12 \\
$2020 / 4 / 6$ & 1.01 & 1.18 & 1.00 & 1.00 & 1.00 & 1.15 & 1.54 & 1.00 & 1.03 & 1.00 & 1.05 \\
$2020 / 4 / 13$ & 1.02 & 1.13 & 1.00 & 1.00 & 1.15 & 1.00 & 1.11 & 1.15 & 1.10 & 1.15 & 1.05 \\
$2020 / 4 / 27$ & 1.02 & 1.16 & 1.00 & 1.00 & 1.00 & 1.23 & 1.35 & 1.05 & 1.00 & 1.00 & 1.06 \\
\hline
\end{tabular}

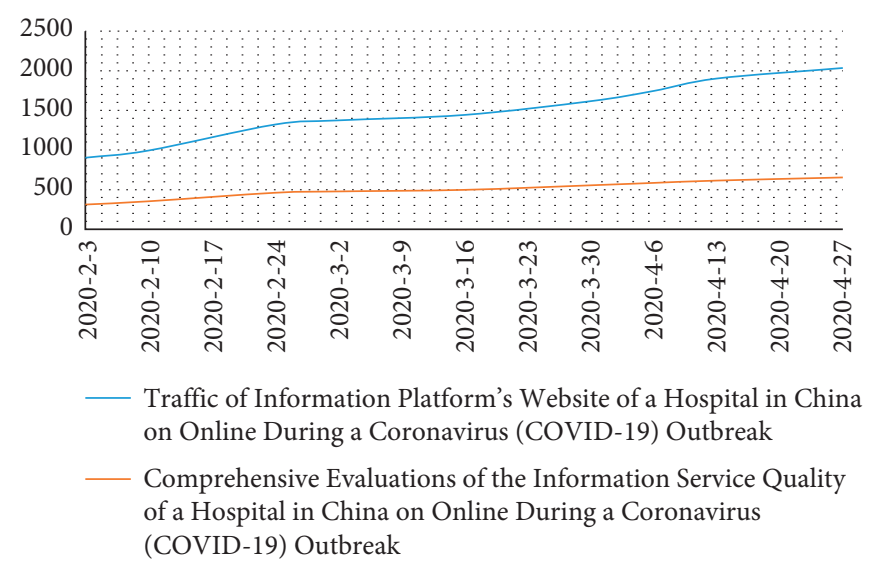

FIgURE 4: Line chart of the correlation analysis of the online website of a hospital in China during the coronavirus (COVID-19) outbreak.

collecting were conducted on the redesigned hospital website, thus increasing the comparability and scientificity of the empirical research survey results presented in this paper.

4.2. Identification of Important Attributes and Dimensions. Participants of the empirical research are selected according to the principles of randomness, feasibility, and objectivity. This article selects participants based on the principle of stratified random sampling and is divided into hospital outpatients, inpatients, staff, public, and professional service personnel based on the principle indicators (including random users, management majors, professors, and website designers). For the composition of participants, see Table 1.

From February 2020 to April 2020, 72 study participants used Internet Explorer 11 as their browser and visited the hospital information website at nine different time points. In this study, the study participants were selected using a stratified random sampling method. Based on the sampling indicators, the participants were divided into four groups: outpatients, inpatients, hospital staff, and the public and professionals.

4.3. Factor Analysis. A detailed review of hospital information services was carried out as part of this research. If the assessment ratings of the participants are considerably different, the average value will be utilized to determine the final result for each participant. As a whole, the averages are as follows: $31.215,35.292,46.053,47.756,49.724,55.459$, 58.500, 61.455, and 65.415. Researchers found that, after adding information and services regarding the coronavirus (COVID-19) epidemic, the hospital's online site got a more complete review of its information services as shown in Table 2 and Figure 3.

Through the binary correlation in the $\mathrm{R}$ programming language, the author conducted a comprehensive evaluation of data of the online website and the flow data of the hospital online website. Table 3 shows the correlation analysis of 


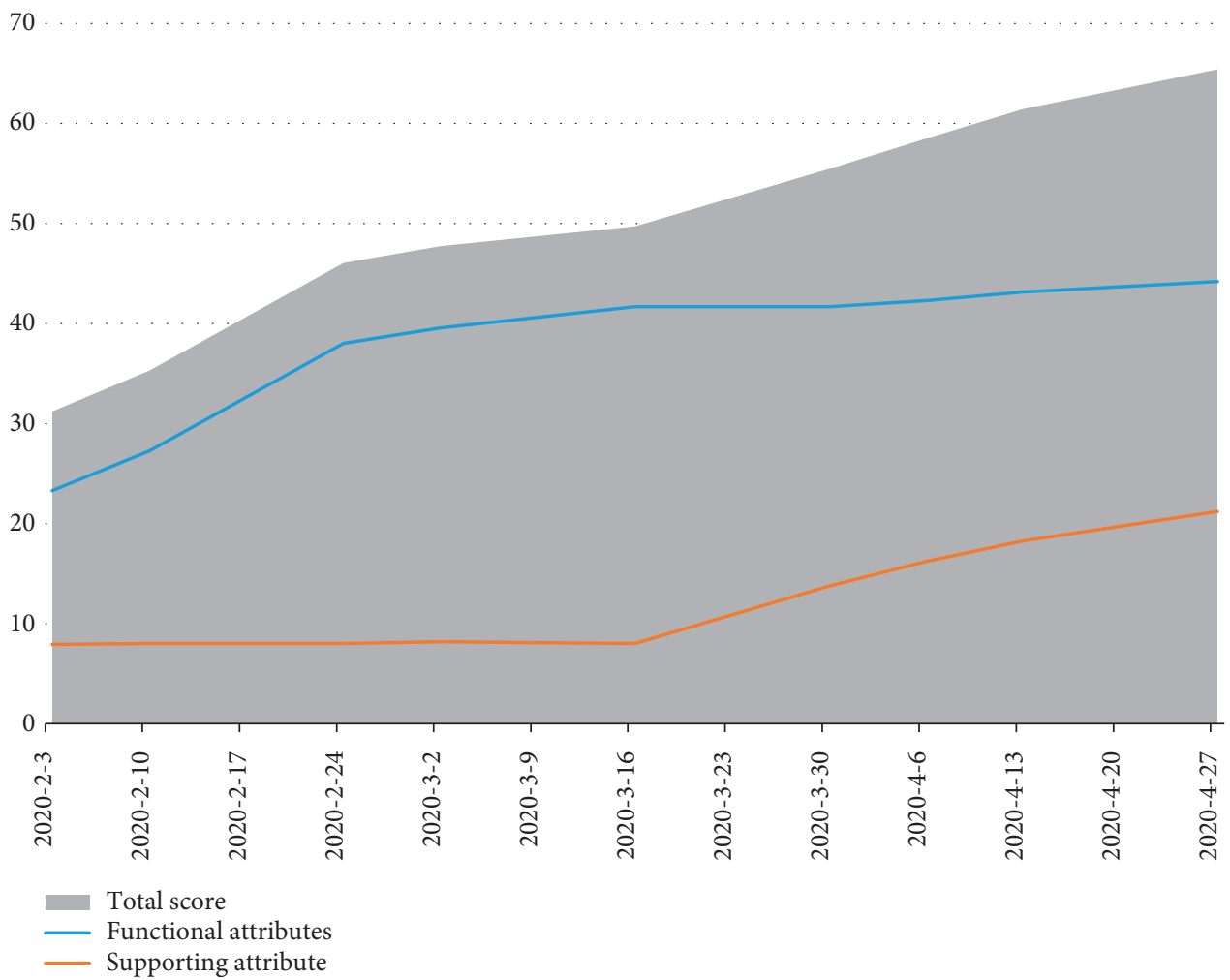

FIgURE 5: Line chart of the functional quality attributes and supporting attribute.

information service and the traffic of a hospital in China online during the coronavirus (COVID-19) outbreak. PV is a comprehensive evaluation of data of the online website. UV is flow data of the hospital's online website. The correlation coefficient between the two is 1 , and we can see from the correlation coefficient that this is a very obvious correlation.

There is a favorable correlation between the overall evaluation of hospital online services and website traffic in this study, and the number of visits changes as the overall rating of services changes as well (see Table 4 and Figures 4 and 5 for details). As a result of this, from March 30 to April 27, 2020, we can observe that improvements in information service function attributes are more rapid than improvements in supporting attributes. If you are looking for a way to improve your services from March 30 to April 27 of 2020, the hospital's information services will be a great place to start! From February 3 through March 16, 2020, you can visit the hospital's website online. The improvement rate of the information service function and support attribute of the hospital website tends to be consistent, and even the support attribute is slightly higher than the function attribute.

\section{Conclusions}

Ensuring effective and efficient management for quality and patient safety is still in its infancy despite increasing pressure on organizations to better and emerging evidence that better board supervision is connected with a higher level of care. Based on the empirical research data and analysis in this article, we calculate the functional quality of the information services of epidemic-related websites on April 27, 2020. The final score was 44.21, which was 1.9 times the original score of 23.29 on February 3, 2020. This reflects the improvement of the function of information services. Enriching information services on epidemic-related websites is the key to improving website information services during epidemic outbreaks. The evaluation scores of information services of epidemic-related websites have increased by 2.1 times, among which the scores of functional attributes of information services have been increased by 1.9 times and the scores of supporting attributes evaluation have been increased by 2.7 times. Moreover, the support attributes of information services for epidemic-related websites will be an important direction for the hospital to improve the quality of services in the next stage. Furthermore, the support characteristics of information services for epidemic-related websites will be an essential path for the hospital to improve service quality in the future.

\section{Data Availability}

The survey results and network traffic data used to support the findings of this study are available from the corresponding author upon request

\section{Conflicts of Interest}

The authors declare no conflicts of interest. 


\section{Acknowledgments}

This work was supported by the Philosophy and Social Science Planning Project of Taizhou City, Zhejiang Province, China (21GHB23). This work was supported by the "San Tai Xin Xiu" Social Scientists Support plan of Taizhou City, Zhejiang Province, China ([2021]7).

\section{References}

[1] China Internet Network Information Center (CNNIC), "Statistical report on internet development in China (the 44th survey report)," 2019, https://cnnic.com.cn/IDR/ ReportDownloads/.

[2] World Health Organization (Who), "Statement on the second meeting of the International Health Regulations (2005) Emergency Committee regarding the outbreak of novel coronavirus (2019-nCoV)," 2020, https://www.who.int/news-room/detail/3001-2020-statement-on-the-second-meeting-of-the-internationalhealth-regulations-(2005)-emergency-committee-regarding-theoutbreak-of-novel-coronavirus-(2019-ncov).

[3] Johns Hopkins University (Jhu), "Coronavirus COVID-19 global cases by the center for systems science and engineering (CSSE) at Johns Hopkins University (JHU)," 2020, https:// gisanddata.maps.arcgis.com/apps/opsdashboard/index.html\#/ bda7594740fd40299423467b48e9ecf6.

[4] Centers for Disease Control and Prevention (Cdc), "How to protect yourself \& others. Coronavirus Disease 2019 (COVID19)," 2020, https:/www.cdc.gov/coronavirus/2019-ncov/ prevent-getting-sick/prevention.html\%20.

[5] A. Parasuraman, V. A. Zeithaml, and L. L. Berry, "A conceptual model of service quality and its implications for future research," Journal of Marketing, vol. 49, no. 4, pp. 41-50, 1985.

[6] S. H. Cai and M. J. Jun, "Internet users' perceptions of online service quality: a comparison of online buyers and information searchers," Managing Service Quality: International Journal, vol. 13, no. 6, pp. 504-519, 2003.

[7] M. M. Jeon and M. Y. Jeong, "Customers' perceived website service quality and its effects on e-loyalty," International Journal of Contemporary Hospitality Management, vol. 29, no. 1, pp. 438-457, 2017.

[8] M. Xie, H. Wang, and T. N. Goh, "Quality dimensions of Internet search engines," Journal of Information Science, vol. 24, no. 5, pp. 365-372, 1998.

[9] M. B. Kolesar and R. W. Galbraith, "A service-marketing perspective on E-retailing:implications for E-retailers and directions for fu tore research. Internet research," Electronic Networking Applieat ions and Policy, vol. 10, no. 5, pp. 424438, 2000.

[10] V. A. Zeithaml, A. Parasuraman, and A. Malhotra, "Service quality delivery through web sites: a critical review of extant knowledge," Journal of the Academy of Marketing Science, vol. 30, no. 4, pp. 362-375, 2002.

[11] M. Wolfinbarger and M. C. Gilly, "eTailQ: dimensionalizing, measuring and predicting etail quality," Journal of Retailing, vol. 79, no. 3, pp. 183-199, 2003.

[12] P. S. Hung, "An empirical study on predicting user acceptance of e-shopping on the Web," Information \& Management, vol. 41, no. 3, pp. 351-368, 2004.

[13] W. W. Harold and A. W. Linda, "SiteQual: an integrated measure of Web site quality," Journal of Enterprise Information Management, vol. 17, no. 6, pp. 430-440, 2004.
[14] J. C. Sweeney and W. Lapp, "Critical service quality encounters on the Web: an exploratory study," Journal of Services Marketing, vol. 18, no. 4, pp. 276-289, 2004.

[15] A. Parasuraman, V. A. Zeithaml, and A. Malhotra, "E-SQUAL: a multiple-item scale for assessing electronic service quality," Journal Of Service Research, vol. 7, no. 3, pp. 213-233, 2005.

[16] J. Liu, G. Shi, J. Zhou, and Q. Yao, "Prediction of College Students' Psychological Crisis Based on Data Mining," Mobile Information Systems, vol. 2021, 2021.

[17] A. Y. K. Chua, D. H .L. Goh, and C. S. Lee, "Mobile content contribution and retrieval: an exploratory study using the uses and gratifications paradigm," Information Processing \& Management, vol. 48, no. 1, pp. 13-22, 2012.

[18] J. Castañeda, "Relationship between customer satisfaction and loyalty on the internet," Journal of Business and Psychology, vol. 26, no. 3, pp. 371-383, 2011.

[19] A. O'Cass and J. Carlson, "An empirical assessment of consumers' evaluations of web site service quality: conceptualizing and testing a formative model," Journal of Services Marketing, vol. 26, no. 6, pp. 419-434, 2012.

[20] Q. Q. Lo and K. H. Chai, "Quantitative analysis of quality management literature published in total quality management and business excellence (1996-201 0)," Total Quality Management and Business Excellence, vol. 23, no. 5, pp. 629-651, 2012.

[21] H. Weiyin, F. K. Y. Chan, J. Y. L. Thong, L. C. Chasalow, and G. Dhillon, "A framework and guidelines for context-specific theorizing in information systems research," Information Systems Research, vol. 25, no. 1, pp. 111-136, 2014.

[22] S. Jun, Z. Yang, Y. Wang, and Y. Zhang, "Rethinking E-commerce service quality: does web site quality still suffice," Journal of Computer Information Systems, vol. 55, no. 4, pp. 62-72, 2015.

[23] Y. Zhao and Q. Tang, "Analysis of influencing factors of social mental health based on big data," Mobile Information Systems, vol. 2021, pp. 1-8, 2021.

[24] J. Lei and R. M. C. P. de Menezes, "Fairness evaluation method of resource allocation based on BPSO multidimensional perspective," Cluster Computing, vol. 22, pp. 4283-4290, 2019.

[25] J. Lei, H. P. Xiao, X. Z. Zhu, and Z. Xu, "Factors influencing information service quality of China hospital: the case study of since 2017 of a hospital information platform in China," Computational and Mathematical Methods in Medicine, vol. 2020, pp. 1-17, 2020. 